INTERNATIONAL JOURNAL OF

SYSTEMATIC BACTERIOLOGY

Vol. 20, No. 2 April 1970 pp. 195-199

Copyright 1970, Iowa State University Press

\title{
SPECIES OF STREPTOMYCES PRODUCING OXYTETRACYCLINE
}

\author{
J.B. Routien
}

Chemotherapeutic Research

Medical Research Laboratories

Chas. Pfizer and Co., Inc.

Groton, Connecticut 06340

ABSTRACT. A review of the nomenclatural status of the species of the genus Streptomyces which are reported in the literatureas producing the antibiotic oxytetracycline.

In a recent paper Kurylowicz and Woznicka (6) listed organisms reputed to produce oxytetracycline. Some comments on the identity of strains claimed to produce this compound should be made. In general, remarks herein are made on the basis of my examination of the cultures or from comparison of the description of the organism, when no culture is available, with information from the literature or information obtained here in regard to the variability of Streptomyces rimosus isolates, mutants or of strains derived from plating out single spores of the original $\mathrm{S}$. rimosus isolate, NRRL 2234. No attempt will be máde here to give detailed comparisons; the amount of data is far too great.

S. albofaciens - this organism is considered to be a strain of S. rimosus, and Cross (1) has indicated that he believes it to be the same as an organism that he named $\underline{S}$. rimosus f. psedudoverticillatus.

S. alboflavus - our efforts to produce oxytetracycline by means of the same original strain and process used by Villax (12) always failed.

S. armillatus (Streptomyces 942) - our study of S942 led to the conclusion that it was a strain of $S$. rimosus, and Waksman (13) believed the same.

S. aureofaciens var. oxytetracycline - this may represent a new variety as claimed, but it has not been available for comparison. 
S. capuensis - the description of this culture has so mañy close resemblances to certain strains of $\underline{S}$. rimosus that it should be considered a strain of that species.

S. gilvus - the description of this strain also indicates identity with S. rimosus.

S. glaucescens - a strain not listed by Kurylowicz and Woznicka, isolated in our laboratory, making oxytetracycline in amounts barely detectable by very sensitive methods, has been identified as this species described by Gauze (2).

S. griseoflavus - the only paper referring to this species is the one by Kochi et al. (5) in which strain W3560 first was suggested as being near $S$. griseoflavus but later in the paper as being $S$. rimosus; this hardly constitutes identification of any oxytetracycline-producing strain as $\underline{\mathrm{S}}$. griseoflavus. My study of this strain shows it to be $S$. rimosus. In the paper by Silvestri (9) referred to by Kurylowicz and Woznicka there is the statement that the cultures he found had morphological and cultural characters similar to those of $S$. rimosus and $S$. griseoflavus. The exact and full meaning of this statement is not clear but would suggest that all are strains of $\mathrm{S}$. rimosus.

S. griseolus - I know of no paper claiming that $S$. griseolus produces oxytetracycline, though Waksman (13) listed it as producing this antibiotic. It should be pointed out, however, that Janot et al. (4) clearly stated that the strain they found that had certain properties of $\underline{S}$. griseolus clearly was not this species.

S. henetus - this was not listed by Kurylowicz and Wozwicka, but it has been described as a new species by Grein et al. (3). I have cultivated the organism and find it to be S. rimosus.

S. hygroscopicus and S. platensis - these were listed separately, but whether they are different species is uncertain. At one time Tresner and Backus (10) thought that S. platensis ". . might more appropriately be regarded..." $\vec{a}$ a variant of $S$. hygroscopicus, but later Tresner, Backus and Hayes (11), using different, new criteria decided that S. platensis was different from S. hygroscopicus. S. platensis is different from any strain of S. rimosus.

S. rimosus - recognized as a distinct species.

Streptomyces sp. S3279 - this is the Pfizer culture collection number of the strain first described and named as S. rimosus (NRRL 2234).

Streptomyces sp. MA590 - this appears to be quite different from S. rimosus. 
Streptomyces sp. W3560 - see remarks under S. griseoflavus.

S. utilis - this shows some properties different from S. rimosus, but the pink color found in the mycelium has been

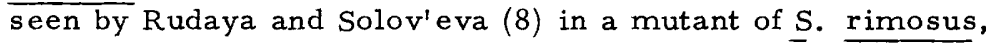
and we have seen this color, also, in a mutant. To the extent that I can reach a conclusion without a transfer of the culture to study, it is a strain of $S$. rimosus.

S. varsoviensis - all isolates of this deposited at the

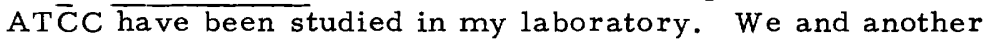
laboratory were unable to demonstrate production of oxytetracycline by the first several strains deposited, but a later (mutant?) one does produce the antibiotic. Our results of certain biochemical tests for classification of streptomycetes were diametrically opposed to the results reported for $S$. varsoviensis. Certain mutations of $\mathrm{S}$. rimosus yielded a strain that looked so much like S. varsoviensis that I concluded that the culture actually should be considered a strain of S. rimosus. Two other outside laboratories, on few criteria than I used, concluded that $S$. varsoviensis is a strain of S. rimosus, and Nitsch (7) concluded that $\underline{S}$. varsoviensis and $\underline{S}$. vendargus were synonyms of S. rimosus.

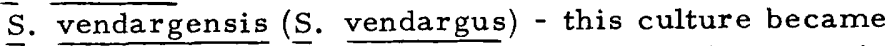
available for study and proved to be undoubtedly a strain of S. rimosus. See also the last sentence in the preceding paragraph pertaining to the paper by Nitsch (7).

In summary, S. glaucescens, S. platensis and Streptomyces sp. MA590 are considered to be different from $\underline{S}$. rimosus; S. aureofaciens var. oxytetracycline may be $\bar{d}_{\text {if }}$ ferent. The cultures listed by other names in the paper by Kurylowicz and Woznicka are either strains of $\underline{S}$. rimosus or should not have been listed because there was some misinterpretation of the results announced in the literature. In the former case, supposedly new species have been named on the basis of slight variations in color of vegetative mycelium or soluble pigment, the shape of chains of spores, carbon utilization pattern, etc. Many of these variations might be expected to occur. Indeed, we have found greater variation than one would expect; for example, one singlespore isolate of $S$. rimosus had a nearly black vegetative mycelium; ultraviolet treatment of spores of the parent $\mathrm{S}$. rimosus in two separate laboratories yielded in each a strain with purple-red vegetative mycelium and a purple soluble pigment, and one of these produced a compound that chromatographically was indistinguishable from oxytetracycline. 


\section{LITERATURE CITED}

1. Cross, T. 1962. Streptomyces species producing oxytetracycline. Nature 195:832-833.

2. Gauze, G.F. 1959. Problems in the classification of antagonistic actinomycetes, D. Gottlieb, Editor of English Edition. The American Institute of Biological Sciences, Washington, D.C.

3. Grien, A., G. Canevazzi and R. Barchiella. 1965. Republic of South Africa Patent Application 650998.

4. Janot, M., H. Penau, G. Hagemann, H. Velu, J. TeilIon et G. Bouet. 1954. Recherche de souches nouvelles de Streptomyces antibiotiques. Annales Pharmaceutiques Francaises 12:440-447.

5. Kochi, M., W. L. Ruigh, R.F. Acker, H. A. Lechevalier and S.A. Waksman. 1952. Antibiotic-producing properties of Streptomyces 3560 , a member of the S. flavus group. Proc. of the National Academy of Sciences 38:383-391.

6. Kurylowicz, W. and W. Woznicka. 1967. Actinomyces (Streptomyces) varsoviensis. Exp. Med. Microbiol. 19:1-9. J. Jeliaszewicz, Editor of American Edition

7. Nitsch, B. "Charakterisierung einiger Oxytetracyclinbildener Streptomyceten und Untersuchungen zur Variabilität von Streptomyces rimosus." Zulassungsarbeit zur wissenschaftlichen Prüfung für das Lehramt an Höheren Schulen in Jahre 1966 in München, Bakteriologischen Institut der Südd. Versuchs-und For schungsanstalt für Milchwirtschaft, Weihenstephan, 805 Freising.

8. Rudaya, S. M. and N.K. Solov'eva. 1961. The formation of a crimson pigment in Actinomyces rimosus. Microbiology 29:551-553. (English translation.)

9. Silvestri, L.G. 1955. L'isolamento dal terreno di ceppi produttori di tetracicline. II. Rinvenimento di ceppi produttori di ossitetraciclina in diverse località della Campagna Romana. Rendiconti Istituto Superior di Sanita 18:1331-1338.

10. Tresner, H.D. and E.J. Backus. 1956. A broadened concept of the characteristics of Streptomyces hygroscopicus. Applied Microbiol. 4:243-250.

11. and Jean A. Hayes. 1967. Morphological spore types in the Streptomyces hygroscopicus-like complex. Applied Microbiol. 15: 637-639. 
12. Villax, I. 1962. Streptomyces lusitanus and the problem of classification of the various tetracyclineproducing Streptomyces. Antimicrobial Agents and Chemotherapy 1962:661-668.

13. Waksman, S. A. 1961. The Actinomycetes. Vol. II. The Williams and Williams Company, Baltimore, Md. 